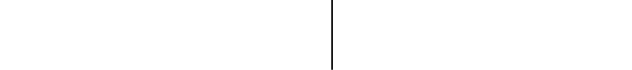

Rev. Latinoam. Psicopat. Fund., São Paulo, v. 10, n. 4, p. 664-676, dez.2007

\title{
Explicação diversa para a origem do câncer, com foco nos cromossomos, e não nos genes, ganha corpo no establishment científico
}

Mônica Teixeira

O conhecimento construído ao longo dos últimos 30 anos na pesquisa sobre o câncer, baseada principalmente no método reducionista, postula que a doença é genética - quer dizer, resultado de mutações ocorridas em certos genes do genoma da célula, especialmente aqueles envolvidos em mecanismos de reparo do DNA. Um eminente e controverso virologista da Universidade da Califórnia em Berkeley, Peter Duesberg, propõe que a transformação da célula normal em célula cancerosa é desencadeada não por mutações genéticas, mas por uma instabilidade em seus cromossomos, tão extensa que leva à formação do que o cientista chama de "nova espécie” celular. Duesberg, desde 1987, afirma que o HIV não causa AIDS.

Palavras-chave: Câncer, genética, oncologia, aneuploidia 
Aneuploidia: essa é a palavra que vem aparecendo na literatura que relata a pesquisa sobre a origem do câncer neste início do século XXI. "Aneuploidia” descreve uma característica muito evidente para os pesquisadores que observam células e tecidos cancerosos no laboratório. Em relação a seus cromossomos, a célula humana normal é chamada “diplóide”, por apresentar dois conjuntos completos de 23 cromossomos; na célula cancerosa, diferentemente, há cromossomos extras, cromossomos faltantes, cromossomos feitos de pedaços fundidos de outros cromossomos. "Uma verdadeira galeria de horror”, escreveu a jornalista de ciência Jean Marx sobre o aspecto do genoma de uma célula cancerosa em artigo publicado em 2002 na revista Science, e muito citado quando o tema da relação entre aneuploidia e câncer aparece. Mas essa extrema variação cromossômica é causa ou conseqüência do câncer? Há duas respostas principais para essa pergunta: uma, a predominante - e que dirige a pesquisa sobre a origem do câncer há 25 anos - afirma que a causa dos cânceres são mutações em genes específicos e que à aneuploidia cabe um papel subsidiário; outra, oposta, postula que a aneuploidia é necessária para "colocar as células no caminho do câncer”. Necessária, aqui, no sentido forte: sem aneuploidia, sustentam esses pesquisadores, não há câncer.

O principal porta-voz e a mais conhecida liderança do segundo grupo é Peter Duesberg. Professor da Universidade da Califórnia em Berkeley, virologista respeitado, Duesberg, em 1970, estudava a relação entre vírus e câncer - uma tendência forte na pesquisa da época (até hoje, o único câncer definitivamente associado a vírus é o câncer do colo do útero, dos quais há tipos desencadeados pelo vírus do papiloma humano). Trabalhando com o vírus relacionado ao aparecimento de sarcomas em aves, Duesberg identificou um gene específico, chamado src, que parecia ser o desencadeador da doença. Alguns anos mais tarde, Harold Varmus, muito importante pesquisador da área, encontrou, em animais e em seres humanos, um gene parecido ao descoberto por Duesberg e que, da mesma maneira que seu contraparente no vírus, poderia iniciar o processo que leva ao câncer em mamíferos. Esse gene, e outros de sua classe, receberam o nome de proto-oncogenes. Mutações nesses genes são fundamentais para o início do processo que leva ao câncer, ensina o mainstream atual. 
Um trabalho de Duesberg, assim, está nos primórdios da visão dominante, aquela à qual ele, há anos, se opõe. O professor de Berkeley - que nasceu na Alemanha - parece ter um gosto pela divergência: em um artigo publicado em março de 1987 na Cancer Research, revista da American Association for Cancer Research, desafiou nada mais, nada menos, do que a bem estabelecida ligação entre AIDS e HIV. Ele argumentou, na época, que nem toda pessoa com AIDS tem HIV; que há quem tenha HIV e não desenvolva a AIDS; e que o uso de drogas recreacionais estava na base da doença. Duesberg não mudou de opinião; mas, na comunidade científica, sua posição não encontrou seguidores.

Diversa é a situação com seu trabalho sobre a relação entre aneuploidia e câncer. Como colocam Stock e Bialy (2003), ambos do Instituto de Biotecnologia da Universidade Autônoma do México, no artigo sobre o tema que publicaram na revista Nature Biotechnology: "Embora a vasta maioria da pesquisa em câncer continue concentrada em 'genes do câncer' particulares, o debate acadêmico está longe de terminar, e visões minoritárias, como muitas vezes ocorre na história da ciência, podem terminar em primeiro plano”. A revista Scientific American, a mais tradicional na divulgação de fatos científicos fora da comunidade de pesquisadores, encomendou a Duesberg um artigo sobre sua teoria, que publicou na edição de maio de 2007. Julgou necessário escrever uma "nota do Editor”, ao lado das linhas de apresentação do autor. Nela, se lê que Duesberg pode ser bem conhecido dos leitores pela afirmação de que HIV não é a causa da Aids; mas que suas idéias sobre "a anormalidade cromossômica como uma causa de raiz para o câncer, em contraste, tem sido ativamente investigada pela ciência dominante”. E acrescenta: "Este artigo [o escrito por Duesberg] de maneira nenhuma representa um endosso da Scientific American às suas teorias sobre a AIDS”. O divergente, afinal, precisa ser levado em conta.

\section{O ponto de vista dominante}

Em 2000, Robert Weinberg e Douglas Hanahan, o primeiro do MIT Massachusetts Institute of Technology, o segundo da Universidade da Califórnia, escreveram um artigo de revisão publicado pela revista Cell, muito citado, que apresenta o ponto de vista dominante sobre o câncer. Ambos são lideranças científicas do campo; Weinberg tem lugar especial por ter identificado, na década de 1980, tanto o primeiro gene da classe dos promotores de tumores - chamados oncogenes, quanto o primeiro da classe dos genes supressores de tumores. Hanahan, por outro lado, estuda o desenvolvimento de câncer em ratos transgênicos. A revisão intitula-se The Hallmarks of Cancer; nela, como resumo do conhecimento reunido em 25 anos de pesquisa sobre a doença, ao autores 
apresentam seis “características adquiridas” necessárias para que células comuns se transformem em células cancerosas. Começa assim:

Depois de um quarto de século de rápidos avanços, a pesquisa em câncer gerou um complexo e rico corpo de conhecimento, revelando que o câncer é uma doença envolvendo mudanças dinâmicas no genoma. As bases foram estabelecidas na descoberta de mutações que produzem oncogenes com ganho dominante de função e genes supressores de tumor com perda recessiva de função; ambas as classes de genes do câncer foram identificadas por meio de sua alteração em células cancerosas humanas e de animais e por sua elisão em fenótipos de câncer em modelos experimentais. (2000, p. 57)

Para os autores, o câncer é, assim, uma doença genética. Células se dividem; a divisão implica a duplicação de seu genoma; durante o processo de cópia, genes podem ser alterados. Alterações se acumulam em duplicações sucessivas; muitas não têm efeitos, mas produzem células cancerosas quando ocorrem em genes de classes específicas. Quando mutações ocorrem nos oncogenes - e, por isso, os tornam ativos -, ou em genes supressores de tumor - e os tornam inativos, iniciase o caminho pelo qual as células descendentes dessas vão adquirindo as seis características de que fala o título do artigo e que levam à formação de tumores. O desenvolvimento de um tumor, explica o texto, é um processo "formalmente análogo à evolução darwiniana”, em que a sucessão de alterações genéticas vai conferindo às células filhas vantagens competitivas que ensejam sua multiplicação e dominância na população de células.

As mutações genéticas que, segundo essa corrente de pensamento, originam o câncer perturbam o que é descrito na literatura como a delicada e precisa maquinaria celular, regida a partir dos genes que estão em seu genoma. Os genes - que são pedaços especiais da molécula de DNA - comandam a produção de proteínas. Para os cientistas, as proteínas realizam tarefas de comunicação: de célula para célula, de célula para seu entorno, e dentro da própria célula. As proteínas envolvidas no desencadeamento do processo de muitos passos que leva ao câncer são, principalmente, aquelas envolvidas em tarefas de vigiar a deparar os erros ocorridos na duplicação do DNA, durante a divisão celular. As proteínas sintetizadas a partir dos genes da classe supressores de tumor, por exemplo, podem sinalizar - quimicamente - para a célula não se dividir mais se erros de duplicação atingiram regiões importantes do genoma. (Essa checagem para a localização de erros no genoma é, também, comunicada por meio de proteínas, produzidas por outros genes). Mas se erros de copiagem acontecem em algum desses genes, toda a cadeia envolvida na supressão do erro pode parar de funcionar - e a célula defeituosa pode começar a multiplicar o seu defeito e dar lugar a outros, numa cadeia que vai sempre resultando em mais defeitos. 
Essa é apenas uma possibilidade, e relatada de maneira grosseira. A relação das chamadas características adquiridas dá uma idéia melhor de como os cientistas pensam a células, os genes e seu funcionamento. São elas: autosuficiência em sinais de crescimento; insensibilidade para sinais de inibição de crescimento; evasão da morte celular programada; potencial ilimitado de replicação; angiogênese sustentada; capacidade de invadir tecidos e criar metástases.

Auto-suficiência em sinais de crescimento - Para que células normais saiam do estado chamado “quiescente” e comecem a se proliferar, é necessário que recebam sinais vindos de fora, de outras células de seu entorno. Células cancerosas, cultivadas em laboratório, mostram grande independência - o vocabulário da biologia é basicamente antropomórfico - desses sinais para começar a se multiplicar. Por exemplo: se os pesquisadores quiserem induzir divisão em células normais, precisam oferecer a elas os chamados "fatores de crescimento”. Um dos processos que ocorrem em células cancerosas e que dá a elas a citada auto-suficiência vem de adquirirem a habilidade de produzir seus próprios fatores de crescimento, dispensando os presentes no ambiente. $\mathrm{Na}$ produção desses fatores de crescimento "autóctones” (que, em células normais, servem para desencadear o crescimento nas células vizinhas), certos oncogenes mutados desempenham papel relevante.

Insensibilidade a sinais de inibição de crescimento - Em um tecido em que há milhões ou bilhões de células, o controle sobre sua multiplicação é absolutamente necessário para que o tecido permaneça parecido consigo mesmo ao longo do tempo e para que seu equilíbrio possa ser mantido. Uma das formas de controle do crescimento celular foi delineada acima: para sair da quiescência, a célula recebe, principalmente, sinais vindos do ambiente em seu entorno - seja de outras células, seja da chamada matriz extracelular, que preenche o espaço entre elas. Da mesma forma, há sinais bioquímicos que agem para inibir a divisão celular. Eles podem ser de dois tipos: os que forçam a célula a sair do estado proliferativo para o estado quiescente, do qual pode reemergir quando o ambiente enviar sinais para isso; ou ser mantida em estado pós-mitose, quando a divisão já está terminada. Para trilhar o caminho que leva uma célula a se tornar cancerosa, ela precisa desenvolver a capacidade de evitar esses sinais, para não ver inibida a sua própria proliferação. Os cientistas afirmam que está demonstrada a ligação de um gene supressor de tumor - o gene do retinoblastoma -, mutado, com esse processo. O gene se chama assim por desencadear, quando inativo por mutação, o câncer chamado retinoblastoma, que atinge a retina e é comum em crianças.

Evasão da morte celular programada - Essa capacidade, dizem os cientistas, está presente "talvez em todos os cânceres”. O programa de morte celular (ou 
apoptose) está presente, pensam os cientistas, em todas as células do corpo. Na revisão, a apoptose é descrita assim: "Uma vez desencadeada por uma variedade de sinais fisiológicos, este programa se desenrola em uma série de passos precisamente coreografados: membranas celulares são rompidas, as estruturas citoplasmáticas e nucleares são quebradas, o citosol é secretado, os cromossomos degradados e o núcleo, fragmentado, tudo de 30 a 120 minutos. No final, o cadáver da célula é engolfado pelas células vizinhas em um tecido e desaparecem, em geral em 24 horas”. A maquinaria da apoptose, diz o texto, compõe-se de sensores - proteínas que fiscalizam o ambiente interno da célula e externo a ela em busca de sinais de que ela deve viver ou morrer; e de executores, comandados por esses sensores, que se encarregam de causar a morte celular. Um exemplo de morte celular programada: quando tomamos muito sol, a pele descasca; o descascar é o resultado de o programa da apoptose ter entrado em ação em razão do grande dano causado ao genoma de milhões de células da pele por efeito do excesso de sol. Para um tumor crescer, as células cancerosas ou pré-cancerosas devem adquirir a habilidade de desativar a pena de morte, à qual são candidatas fortes dado o fato de seus genomas estarem cheios de defeitos. Os cientistas sabem que a perda da função de um gene muito conhecido da classe dos genes supressores de tumor - o p53 - dá às células cancerosas a capacidade de escapar do corredor da morte celular.

Potencial de replicação ilimitado - As três habilidades do câncer listadas acima levam a um despareamento entre a capacidade de crescer de uma célula e os sinais que vêm do ambiente interno ou externo a ela. Mesmo tendo adquirido essas habilidades, ainda assim a célula, em um certo momento, vai parar de se duplicar. É a senescência, característica das células normais correlacionada ao funcionamento normal de dois genes supressores de tumor: o do retinoblastoma e o p53; de acordo com os autores, esse "programa” parece operar independentemente de qualquer sinalização célula a célula: é interno à célula. Para se tornar cancerosa, uma célula deve contornar a senescência e se tornar... imortal - ou seja, deve adquirir a capacidade de se replicar indefinidamente, o que é feito quando ocorrem mutações em genes determinados.

Angiogênese sustentada - Todas as células dependem de oxigênio e nutrientes que são fornecidos através da vascularização dos tecidos. Isso obriga todas as células de um tecido a estar, em média, a pelo menos milímetros de distância de um vaso capilar. Quando um tumor cresce, suas células vão se distanciando dos vasos que alimentam o tecido. Por isso, as células cancerosas, ou pré-cancerosas, devem providenciar o surgimento de vasos capilares que as nutram. Sem isso, um tumor não cresce. Ocorre que, no tecido sadio, a angiogênese - nascimento de vasos - é também um processo cuidadosamente 
regulado. Estudando o desenvolvimento de cânceres em ratos, os cientistas do campo aprenderam que é no meio do caminho para o câncer completamente desenvolvido que a capacidade de induzir a formação de vasos capilares é adquirida. O mecanismo não está completamente entendido, dizem os autores da revisão; mas sabe-se que, mais uma vez, a perda de função do p53, em um certo tipo de tumor, leva ao bloqueio da produção de um fator inibidor de formação de vasos.

Invasão de tecidos e metástase - Os autores admitem que este é o território menos conhecido - que mecanismos dão às células cancerosas primeiro, a habilidade de invadir os tecidos próximos e depois colonizar outros tecidos, distantes do tumor originário. No entanto, $90 \%$ das mortes por câncer se devem a esta capacidade. A razão da ignorância, informam, é o fato de a pesquisa em câncer ter se ocupado em estudar os mecanismos intracelulares in vitro e "voltou as costas" ao fato biológico de que o desenvolvimento do câncer envolve mudanças nas interações entre as células pré-cancerosas e os tecidos em sua vizinhança.

As seis características adquiridas, que fazem de um tumor um câncer, capaz de crescer até se tornar letal, todas surgem, nessa visão, de mutações genéticas. De acordo com esta teoria, no mínimo quatro e até sete dessas mutações são necessárias, acumuladas, no genoma das células de um mesmo tecido, para o desenvolvimento do câncer.

\section{A visão divergente de Duesberg}

Não é que os cientistas que trabalham para acumular mais conhecimento sobre a relação entre alterações genéticas e a origem e o desenvolvimento do câncer, em sua centena de variações, ignorem ou não levem em conta o fato que, para Duesberg, é capital. A aneuploidia, ou instabilidade genômica, e seu resultado - o fenótipo alterado das células de tumores, e que vai se alterando cada vez mais à medida que a doença progride - é citada como uma espécie de conseqüências das mutações genéticas. Nas palavras de Stock e Bialy (2003), do campo de Duesberg, para os cientistas do lado das mutações, são elas que "iniciam e mantêm o fenótipo alterado das células cancerosas”. No paper de Weinberg e Hanahan (2000), essa instabilidade do genoma aparece depois de detalhadas as seis capacidades adquiridas das células que levam ao estabelecimento irreversível do câncer, para introduzir um problema da teoria apresentada: o fato de mutações em genes específicos, para eles na base de todos os fenômenos que transformam a célula comum em célula cancerosa, serem um processo ineficiente e fastidioso, dado o funcionamento do sistema complexo de proteínas que vigiam e reparam 
o DNA. Além desse sistema, observam os autores, há ainda outro, que zela pela manutenção da ordem do cariótipo (cariótipo é o nome dado ao conjunto dos cromossomos de uma célula) nos momentos críticos da vida da célula especialmente durante o momento crítico da organização dos cromossomos na mitose. “Juntos”, escrevem, "esses sistemas garantem que mutações sejam eventos raros, tão raros que as múltiplas mutações conhecidas por estarem presentes no genoma de células tumorais muito improvavelmente ocorrerão durante o período de uma vida humana”.

O artigo diz que, "para alguns” - Duesberg não é citado nem uma vez -, o fato de os cânceres, na realidade, aparecerem com freqüência substancial se deve à “crescente mutabilidade” das células tumorais, que dá a seu crescimento a velocidade necessária para que o câncer apareça em décadas. Mas, de novo, o artigo atribui essa mutabilidade crescente a alterações em genes específicos. O paper não se compromete com essa versão, e descreve a instabilidade genômica como "o meio que capacita populações de células pré-malignas em desenvolvimento a obter os seis objetivos biológicos”.

Para Duesberg e outros, a aneuploidia tem bem outro papel. O câncer, para o grupo, é uma doença cromossômica - e não genética. Em dois de seus artigos - o já mencionado, na Scientific American, de 2007, e outro, de 2005, publicado na revista Cellular Oncology, intitulado "The chromosomal basis of cancer" -, o virologista segue uma mesma estrutura de argumentação. Para mostrar que o pensamento sobre o câncer não foi sempre o mesmo, Duesberg lembra que, antes da prevalência da teoria da mutação genética, do início do século até os anos 1960, os pesquisadores da área investigavam se o câncer não poderia ser originado por certos vírus - ele próprio sendo um deles. "Propomos que o problema do câncer ainda não está resolvido”, ainda que “o debate venha sendo monopolizado pelas teorias convencionais da mutação genética” (2005). Vale a pena ler o resumo apresentado da "teoria convencional":

Essas teorias sobre a base genética postulam que o câncer é causado pela expansão clonal de células que acumularam entre quatro a sete mutações específicas e complementares durante o período de vida do paciente. Além disso, essas teorias postulam que, uma vez geradas por essas de quatro a sete mutações, as células cancerosas progridem independentemente dentro dos cânceres "clonais” para formar ainda mais cânceres malignos e heterogêneos via ainda mais espontâneas mutações - enquanto as células normais do mesmo paciente permanecem não mutadas. (2005, p. 293)

Duesberg observa também que, apesar de muitos esforços de pesquisadores, desde o estabelecimento dessa teoria - há 30 anos -, "para demonstrar que alguns desses oncogenes podem, sozinhos, transformar células normais em células malignas, nenhum conseguiu” (2007, p. 35-6). Essa dificuldade de 
transformar uma célula normal em célula cancerosa ou pré-cancerosa também é observada no paper de Weinberg. Para a ciência experimental, esse é um obstáculo. Mas há outros.

\section{O que a teoria da mutação genética não explica, segundo Duesberg}

O cientista alemão, que mantém colaboração também com colegas da Universidade de Heidelberg, uma das mais importantes de seu país natal, sustenta que "mudanças no número e na estrutura de cromossomos inteiros, mais que em genes isolados, são suficientes para iniciar e sustentar a malignidade” (2007). Para ele, a teoria também explica as discrepâncias da teoria da mutação genética.

Não se herda o câncer - Não se nasce com câncer; adquire-se câncer, com o avanço da idade. Esse fato é paradoxal para a teoria convencional. Para ela, o câncer deveria ser comum em recém-nascidos (a incidência de câncer em bebês de até um ano é de 0,24 em mil homens por ano; em adultos entre 80-84 anos, de 30,83). Ele dá um exemplo: um bebê que tenha herdado três mutações ligadas ao câncer de cólon (o mais estudado de todos, aliás) de seu pai e mais duas de sua mãe, nasceria com cinco das seis mutações que os pesquisadores da teoria das mutações dizem serem as desencadeadoras desse câncer. Essa uma, o bebê poderia adquirir logo e, assim, desenvolver o câncer de cólon em idade precoce - se apenas mais uma mutação em genes específicos ocorrer em qualquer uma das bilhões de células de seu intestino. Mas isso não acontece - não há câncer de cólon em recém-nascidos, e os cânceres são extremamente raros em crianças e adolescentes. Filhotes de ratos de laboratório que nascem com subconjuntos dessas seis mutações não desenvolvem câncer de cólon, para surpresa dos pesquisadores envolvidos no experimento. Além disso, se existissem genes de câncer hereditários, gêmeos deveriam ter taxas de câncer similares, o que também não acontece.

Há cancerígenos que não causam mutações genéticas - Substâncias cancerígenas são agentes químicos ou físicos que desencadeiam câncer. Há os que são mutagênicos, e os que não são - e aí está a questão para a teoria da mutação genética. De acordo com Duesberg e colaboradores, amianto, dioxinas, alcatrão, hidrocarbonetos aromáticos - entre outros cancerígenos - não causam mutações genéticas mas, mesmo assim, causam câncer. Como, então, causam câncer? A teoria genética não explica.

Cancerígenos levam muito tempo para causar câncer - Embora os agentes cancerígenos que causam mutação, o façam in vitro muito rapidamente, levam 
longo tempo para causar câncer em seres vivos. O mesmo ocorre com os cancerígenos que não causam mutações. Como diz um cientista citado por ele: "Claramente, não podemos afirmar que sabemos o que torna uma célula em uma célula cancerosa até que entendamos por que o tempo transcorrido para a gênese do câncer seja quase sempre tão extraordinariamente longo”. Um exemplo: os cânceres sólidos que se desenvolveram em sobreviventes de Hiroshima e Nagasaki vinte anos depois da explosão das bombas atômicas. Além disso, sempre segundo Duesberg, descobriu-se que a dose de cancerígeno necessária para iniciar o processo que leva à formação de tumores, muitos anos depois, é muito menor do que a necessária para mutar qualquer gene específico.

Cancerígenos, causem ou não mutações, induzem aneuploidia - Sempre que uma célula é tratada com um agente cancerígeno, seus cromossomos se tornam instáveis e passam a apresentar taxas mais altas de quebras ou perdas. Para Duesberg, essas descobertas "sugerem que cancerígenos funcionam mais como ‘aneuploidígenos' do que como mutagênicos”. Mesmo os cancerígenos que causam mutações podem introduzir aneuploidia. Por exemplo: os hidrocarbonetos aromáticos, que não causam mutações, destroem as proteínas que separam simetricamente os cromossomos duplicados durante a mitose; já a radiação, que é mutagênica, age porque quebra o DNA; quando o mecanismo de reparo entra em ação, ao tentar consertar a cadeia, introduz erros ou rearranjos na seqüência de nucleotídeos. Na visão de Duesberg, “o denominador comum de todos os cancerígenos parece ser o desencadeamento de aneuploidia aleatória”.

Correlações exatas entre câncer e aneuploidia - "Se a aneuploidia é apenas um efeito colateral do câncer, então as mudanças cromossômicas nos cânceres de pessoas diferentes deveriam ser aleatórias”, diz Duesberg na Scientific American. Mas, com o uso de novas técnicas de exame massivo de tecidos e genes, diz ele, “começam a se revelar padrões no caos das células cancerosas”: mudanças cromossômicas específicas na maior parte dos cânceres de certo tipo. Um destes é citado por Stock e Bialy (2003, p. 13): em células de hamsters transformadas em cancerosas in vitro, "e em tumores derivados dessas células in vivo", 79\% das transformadas tinham três cromossomos 3, 59\% só tinham um cromossomo 10; e metade delas tinha as duas mudanças - "muito mais do que os $0,6 \%$ esperados se as aneussomias fossem o resultado de desequilíbrios cromossômicos aleatórios”. O achado é do grupo de Duesberg. Mas em seu próprio texto, não é esse resultado que cita, e sim o de um grupo da Universidade da Karolinska, na Suécia, que examinou dez pacientes com um tipo de linfoma, nos quais foram encontrados troca de trechos entre os cromossomos 3, 13 e 17 e perdas ou ganhos de pedaços específicos dos cromossomos 7 e 20 . O ponto dos padrões de aneuploidia segundo cânceres é importante: por não terem sido 
encontrados, a hipótese de que a instabilidade de cromossomos foi abandonada por seus iniciadores, os biólogos alemães David von Hansemann, no começo do século XX. O primeiro observou que todos os cânceres contêm cromossomos anormais; o segundo, Boveri, chegou à hipótese estudando o desenvolvimento de embriões; observou que aqueles como cariótipo muito instável não sobrevivem; mas que certos ganhos ou perdas nos cromossomos podem dar a uma célula e a seus descendentes a capacidade de se multiplicar e dar origem ao câncer.

Certas características do câncer não contribuem para sua sobrevivência Duesberg chama a atenção para o fato de a capacidade de criar metástases não ajudar as células de um tumor a competir por sua sobrevivência em seu lugar originário. Ocorre que, à luz de Darwin, mutações genéticas individuais só serão conservadas no tumor se a mutação trouxer vantagens - o que não é o caso. Mas como a aneuploidia altera, de uma só vez, centenas ou milhares de genes, essas características não vantajosas surgem junto com outras, vantajosas, trazidas por ela.

Células cancerosas mudam mais depressa do que os genes - A taxa de mutação de genes é muito lenta para explicar a progressão da doença e as mudanças rápidas no cariótipo das células, quando o câncer está bem instalado. Quando maior a aneuploidia, mais depressa aparecem novas mudanças cromossômicas. Isso explica, segundo Duesberg, a evidência clínica de que não há tumores iguais, mesmo quando se originaram do mesmo tecido, ou foram induzidos experimentalmente da mesma maneira.

Essas falhas na teoria da mutação genética, na visão de Duesberg, levaramno a propor a teoria do câncer como uma doença cromossômica.

\section{O câncer como doença cromossômica}

É simples: o câncer é disparado por agentes cancerígenos, por raras síndromes genéticas ou por erros acidentais ocorridos na mitose, por induzirem aneuploidias aleatórias. Pelo fato de qualquer aneuploidia afetar milhares de genes de uma só vez, e a produção de suas proteínas, a aneuploidia inicial gera mais aneuploidia; e assim, há uma fonte constante de variação. Essas células variantes são selecionadas, de acordo com critérios darwinianos clássicos; finalmente, surgem da seleção células neoplásicas viáveis e competitivas - verdadeiras espécies novas, até mesmo parasitárias, com cariótipos instáveis. Com o progresso do tumor, reorganizações aleatórias dos cromossomos podem gerar características não selecionadas, como a capacidade de produzir metástases e resistência a drogas. Assim, observa o virologista, as perspectivas de drogas que tenham como alvo apenas certos genes não são boas; por outro lado, como muito tempo 
transcorre entre o início da aneuploidia e o tumor agressivo, oferece "uma janela ampla de oportunidades para a detecção e remoção cirúrgica do câncer, antes que ele entre no estágio neoplásico”. A aneuploidia também poderia ser usada como um critério para separar tumores benignos de malignos. Mais: buscando com mais afinco por cancerígenos, a possibilidade de prevenção vai se ampliar.

Tomara. Mas... o papel do psiquismo no desencadear e no refrear dos cânceres - nenhum pesquisador está disposto a investigar?

\section{Referências}

Duesberg, Peter et al. The chromosomal basis of cancer. Cellular Oncology, v. 27, p. 293-318, 2005.

Duesberg, Peter. Chromosomal chaos and cancer. Scientific American, p. 35-41, May 2007.

GRIMm, David. Disease backs cancer origin theory. Science, v. 306, p. 389, 15 October 2004.

Hanahan, Douglas e Weinberg, Robert A. The Hallmarks of Cancer. Cell, v. 100, p. 5770, January 7, 2000.

MARx, Jean. Debate surges over the origins of genomic defects in cancer. Science, v. 297, p. 544-6, July 26, 2002.

Stock, Robert P. e Bialy, Harvey. The sigmoidal curve of cancer. Nature Biotechnology, v. 21, p. 13-4, January 2003.

\section{Resumos}

El conocimiento construido a lo largo de los últimos 30 años en la investigación sobre el cáncer, basada principalmente en el método reduccionista, postula que la enfermedad es genética - quiere decir, resultado de mutaciones ocurridas en ciertos genes del genoma de la célula, especialmente aquellos envueltos en mecanismos de reparo del DNA. El eminente y controvertido virólogo, profesor de biología celular e molecular de la Universidad de California en Berkeley, Peter Duesberg, propone que la transformación de la célula cancerosa es desencadenada no por mutaciones genéticas e si por una inestabilidad en sus cromosomas, tan extensa que lleva a la formación de lo que el científico llama "nueva especie" celular. Duesberg desde 1997, afirma que el VIH no causa SIDA.

Palabras claves: Cáncer, genética, oncología, aneuploidia 
Les connaissances construites au long des trente dernières années dans la recherche sur le cancer reposant surtout sur une approche réductionniste, affirment que la maladie est d'origine génétique - soit, le résultat de mutations qui ont eu lieu dans certains gènes du génome de la cellule, particulièrement dans ceux associés aux mécanismes de réparation de l'ADN. Un virologiste éminent et controverse, professeur de biologie cellulaire et moléculaire de l'Université de Californie à Berkeley, Peter Duesberg, soutient que la transformation de la cellule normale en cellule cancéreuse résulte non d'une mutation génétique, mais d'une instabilité chromosomique si considérable qu'elle mène à la formation de ce que le chercheur appelle une “nouvelle espèce” de cellules. Duesberg défend depuis 1987 que le VIH n’est pas à l'origine du SIDA.

Mots clés: Cancer, génétique, oncologie, aneuploïde

The knowledge built up over the last 30 years of research on cancer and based mainly on the reductionist method, postulates that the disease is genetic. In other words, it results from mutations that have occurred in certain genes of the genoma of the cell, especially of those involved in mechanisms of repairing DNA. One eminent and controversial virologist and professor of cell and molecular biology at the University of California in Berkeley, Peter Duesberg, suggests that the change from a normal cell into a cancerous cell is triggered off not by genetic mutations but by instability in the chromosomes, so extensive that it leads to the formation of what Duesberg calls a 'new species' of cell. This same scientist has also asserted, since 1987, that HIV does not cause Aids.

Key words: Cancer, genetic, oncology, aneuploidia

\section{MôNica TEIXEIRA}

Jornalista na TV Cultura (Fundação Padre Anchieta, São Paulo, SP, Brasil) e coordenadora do Núcleo de Pesquisas e Desenvolvimento de Novas Tecnologias para a TV pública; psicanalista; coordenadora do Laboratório de Saúde Mental da Associação Universitária de Pesquisa em Psicopatologia Fundamental (São Paulo, SP, Brasil); organizadora do livro Universidade e governo: professores da Unicamp no período FHC (Escuta, 2003).

Av. Higienópolis, 318/13

01238-001 São Paulo, SP

e-mail: armonica@uol.com.br

Versão inicial recebida em novembro de 2007 Versão aprovada para publicação em novembro de 2007 